\title{
USO DO PORTFÓLIO COMO FERRAMENTA AVALIATIVA EM UMA DISCIPLINA DO CURSO DE NUTRIÇÃO DA UNIVERSIDADE FEDERAL DE MINAS GERAIS
}

\author{
Aline Viveiros ${ }^{1}$ \\ Rita de Cássia Marques ${ }^{1}$
}

\section{RESUMO}

No contexto da avaliação formativa, o portfólio se mostra como uma alternativa viável para a adoção de ferramentas que coloquem o aluno no centro do próprio processo de aprendizagem. Assim, a disciplina Alimentação e Cultura adota o portfólio como instrumento avaliativo, que deve partir de uma reflexão crítica sobre os assuntos abordados ao longo das atividades. A avaliação dos trabalhos é feita pela leitura dos registros feitos pelos alunos sobre os temas tratados na disciplina. Como ponto negativo sobre essa ferramenta, pode-se citar a dificuldade dos discentes em entender que a avaliação deve ser feita ao longo do semestre e que é necessária também a autoavaliação, fazendo os ajustes necessários para a melhora do processo de aprendizagem. Mesmo diante de algumas limitações, o uso do portfólio justificase por possibilitar a criação de uma atitude reflexiva sobre o processo de aprendizagem por parte dos alunos.

Palavras-chave: Avaliação educacional. Educação superior. Ensino. Portfólio.

Recebido em: 10/05/2016 Aprovado em: 18/01/2017

\footnotetext{
${ }^{1}$ Escola de Enfermagem, Universidade Federal de Minas Gerais, Belo Horizonte, MG, Brasil.
} 


\title{
USE OF PORTFOLIO AS AN EVALUATING TOOL IN A DISCIPLINE OF THE NUTRITION COURSE AT THE FEDERAL UNIVERSITY OF MINAS GERAIS
}

Aline Viveiros

Rita de Cássia Marques

\begin{abstract}
Within the context of formative evaluation, portfolio is a viable alternative for the adoption of tools that place students at the center of their own learning process. Thus, the discipline 'Food and Culture' adopts the portfolio as evaluation instrument, which should be started from a critical reflection on the issues addressed throughout the activities. The evaluation of works is done by reading the records made by students about the topics covered in the discipline. As a negative point about this tool, it is possible to mention the difficulty students have in understanding that the evaluation has to be done throughout the semester, and that the self-evaluation performance is also necessary, in order to enable them to make the required adjustments to improve their learning process. Even facing some limitations, the use of the portfolio is justified by the possibility of creating a reflexive attitude by the students about their own learning process.
\end{abstract}

Keywords: Educational evaluation. Higher education. Teaching. Portfolio. 


\section{INTRODUÇÃO}

A avaliação deveria ter como objetivo o educar. Entretanto, os processos avaliativos ainda valorizam, em demasia, a questão do acerto e adotam critérios baseados na memorização e na reprodução do que é dito em sala de aula pelo professor (BRUZZl et al., 2001). Scriven (1978) propôs que a avaliação não partisse dos objetivos dos planos de ensino para desenvolver os critérios avaliativos, mas que esses objetivos fossem determinados por meio das produções dos alunos, em um dado contexto educacional. Assim, a partir dos estudos de Scriven, a avaliação passa a ser vista não somente como uma forma de análise de resultados, com vistas a se chegar a conclusões dicotômicas como 'sim'/'não', 'aprovado'/'reprovado', características dos aspectos somativos. Adicionalmente, emerge o conceito de avaliação formativa, que é aquela que avalia o processo de ensino-aprendizagem constantemente e permite que ajustes sejam feitos ao longo do desenvolvimento do discente (SCRIVEN, 1978). Contudo, cabe destacar que ambos os processos avaliativos não devem ser vistos como excludentes um com relação ao outro, mas entendidos de forma complementar (OLIVEIRA et al., 2007).

Nesse contexto de avaliação formativa, buscam-se novas ferramentas avaliativas que sustentem a aprendizagem ao invés de desmotivá-la (BRUZZI et al., 2001). Assim, o portfólio surge como alternativa para os processos avaliativos com o intuito mencionado acima. De acordo com o dicionário Michaelis (2016), a palavra 'portfólio' é definida como uma pasta para guardar amostras, álbuns e folhetos. Em algumas áreas, como as artes, a arquitetura e o jornalismo, o uso do portfólio como forma de armazenar as melhores produções do profissional já é consagrado há vários anos (BRUZZI et al., 2001). Porém, na área educacional, essa "pasta" ganha um caráter que vai além da reunião de informações como em um curriculum vitae. 0 portfólio é entendido como uma experiência de construção individual e coletiva, exercitada no percurso de uma disciplina, que apresenta trabalhos e objetivos específicos do autor (HYPOLLITO, 1999; BITTENCOURT; BELLI, 2006).

Dessa forma, a adoção dessa ferramenta no contexto da aprendizagem permite ao aluno criar autonomia e vivenciar uma experiência que vai além das questões avaliativas. Assim, o discente pode construir o material pedagógico que vai utilizar com aquilo que the parece mais adequado, de maneira a produzir os próprios questionamentos e se aprofundar nas questões que mais lhe interessam (BITTENCOURT; BELLI, 2006). Não obstante, esse tipo de ferramenta exige do professor e do discente uma postura reflexiva. Com relação ao professor, este deverá entender bem o que significa o portfólio, compreender os objetivos da ferramenta 
e saber redirecioná-los ao longo do percurso, encorajando os alunos nas produções, interesses particulares e experiências. Quanto ao discente, este deve analisar, refletir e julgar a qualidade das produções que realiza de maneira a buscar o aprimoramento delas (MIRANDA, 2011).

O curso de Nutrição da Universidade Federal de Minas Gerais (UFMG), criado em 2003, além de ter como objetivo formar um profissional crítico-reflexivo, encoraja, no projeto pedagógico, o uso de critérios avaliativos que permitam ao aluno uma perspectiva mais autônoma do próprio processo de aprendizagem, centrada no aprender a aprender (UFMG, 2003). A autoavaliação é vista na concepção do curso como um "processo contínuo e orientado para os aspectos cognitivos, de habilidades e de atitudes" (UFMG, 2003, p. 19). Assim, de forma coerente com esse perfil profissional e com a proposta pedagógica do curso, as disciplinas Alimentação e Cultura e Ética e Cultura, dentre outras, adotam o portfólio como elementochave para a avaliação dos acadêmicos.

Destarte, essas disciplinas lidam com discentes em processo de adaptação ao meio acadêmico, principalmente na disciplina Alimentação e Cultura, ministrada no primeiro período, em que muitos alunos ainda não se desligaram dos comportamentos e da rotina vivenciadas no ensino médio. Nesse momento inicial do percurso curricular do curso de Nutrição, de acordo com o projeto pedagógico, o aluno é conduzido para um olhar mais amplo sobre a profissão que escolheu. Assim, os discentes aprendem sobre aspectos relativos à cultura alimentar, à produção e à distribuição de alimentos, dentre outros conteúdos que caracterizam o que existe à volta deles sobre o alimento e suas relações socioambientais (UFMG, 2003). Dessa forma, adotar o portfólio pode ser uma forma eficiente de introduzir esses indivíduos no contexto universitário, estimulando-os a refletirem sobre os assuntos abordados de forma ampliada nas disciplinas, de um modo diferenciado, e, ao mesmo tempo, a pensarem sobre o próprio processo de formação.

Dito isso, este estudo tem por objetivo relatar a experiência do uso do portfólio em uma das disciplinas do curso de Nutrição da UFMG. Assim, espera-se que este trabalho possa contribuir para a reflexão sobre a adoção dessa ferramenta como uma possível alternativa ao se pensar em instrumentos que coloquem o estudante no centro do próprio processo de aprendizagem. 


\section{ALIMENTAÇÃO E CULTURA}

A disciplina Alimentação e Cultura é uma das poucas dentro do curso de Nutrição da UFMG que utilizam o portfólio como critério avaliativo. Está localizada no primeiro período do curso, e, por isso, a adoção do portfólio pode se mostrar como uma importante ferramenta para o despertar da crítica e da reflexão dos acadêmicos frente ao processo de aprendizagem que iniciam. Com carga horária de 45 horas, tem como objetivo geral possibilitar ao aluno "conhecer a história da alimentação humana, incluindo os processos de industrialização e massificação das informações e dos hábitos alimentares sob uma ótica crítica e questionadora" (UFMG, [20-]). (QUADRO 1).

Quadro 1 - Conteúdo programático da disciplina Alimentação e Cultura, do curso de Nutrição da UFMG, 2014 a atual.

\begin{tabular}{ll}
\hline \multicolumn{1}{c}{ CONTEÚDo } & \multicolumn{1}{c}{ ATIVIDADE DIDÁTICA } \\
\hline $\begin{array}{l}\text { Alimentação na pré-história e humanização do } \\
\text { ato de alimentar - Comensalidade }\end{array}$ & $\begin{array}{l}\text { Introdução ao portfólio e à disciplina, exibi- } \\
\text { ção de filme e discussão }\end{array}$ \\
$\begin{array}{l}\text { Hábitos alimentares dos pais e avós - Influências } \\
\text { culturais negras, europeias e indígenas no coti- } \\
\text { diano }\end{array}$ & Seminário discente \\
$\begin{array}{l}\text { A cultura alimentar mediterrânea e dos árabes } \\
\begin{array}{l}\text { Uma história da maneira de comer: o caso da } \\
\text { França }\end{array}\end{array}$ & $\begin{array}{l}\text { Aula expositiva, exibição de filme } \\
\text { de filme }\end{array}$ \\
$\begin{array}{l}\text { A influência da cultura no surgimento e na mo- } \\
\text { dernização dos restaurantes }\end{array}$ & Aula expositiva, exibição de filme \\
$\begin{array}{l}\text { Fast-foods, os tempos da alimentação rápida dexto, exibição } \\
\text { Mídia e alimentos: alimentação infantil (mídia, }\end{array}$ & Aula expositiva, exibição de filme \\
cultura e industrialização) & Aula expositiva e exibição de filme \\
$\begin{array}{l}\text { Discussão do livro O mundo está gordo. O que gastronomia hoje? } \\
\text { andamos comendo? }\end{array}$ & $\begin{array}{l}\text { Discussão de texto, apresentação de ativida- } \\
\text { de extraclasse utilizando registro fotográfico }\end{array}$ \\
\hline
\end{tabular}




\begin{tabular}{ll}
\hline \multicolumn{1}{c}{ CONTEÚDO } & ATIVIDADE DIDÁTICA \\
\hline $\begin{array}{l}\text { Cozinha brasileira: contribuição indígena, africana } \\
\text { e portuguesa }\end{array}$ & Aula expositiva \\
História dos alimentos - O que vimos no mercado & Discussão das visitas à comunidade \\
$\begin{array}{l}\text { Atividade de integração de disciplinas: alimenta- } \\
\text { ção e saúde: hábitos e vícios alimentares }\end{array}$ & Seminário discente \\
\hline
\end{tabular}

Fonte: elaborado pelas autoras, 2016.

Com relação à metodologia, esta se processa numa perspectiva participativa e construtora. Por isso, somando-se às aulas expositivas, outras atividades são desenvolvidas, como a realização de quatro seminários e grupos de discussão, exibição de seis filmes e duas visitas junto à comunidade (Mercado Central e Museu de Artes e Ofícios, em Belo Horizonte). O registro dos assuntos abordados durante as atividades da disciplina e de outras temáticas de interesse do discente é feito na forma de portfólio, que é avaliado parcialmente ao longo do semestre, atribuindo à atividade avaliativa um caráter contínuo e progressivo (UFMG, [20-]).

\section{O USO DO PORTFÓLIO}

O interesse pela adoção do uso do portfólio como ferramenta avaliativa na disciplina Alimentação e Cultura vem desde o ano de 2006 e partiu do descontentamento da docente responsável pela atividade com a utilização de processos classificatórios, marcadamente excludentes, como a tradicional aplicação de provas e exames. Além disso, como os conteúdos abordados nessa disciplina são mais flexíveis, abriu-se espaço para diversas possibilidades didáticas. Embora seja uma produção autônoma do aluno, o uso do portfólio para a disciplina não pode ser feito sem critério, consistindo apenas numa pasta onde os alunos inserem informações aleatórias sobre os temas trabalhados. A crítica e a reflexão são estimuladas durante todo o processo.

Considerando-se que o portfólio é uma ferramenta pouco usual na vida dos discentes e que muitos deles entram em contato pela primeira vez com essa ferramenta didático-avaliativa na disciplina Alimentação e Cultura, é necessário que se dedique um tempo para trabalhar 
as concepções desse instrumento. Dessa forma, no encontro inicial da disciplina, é feita a explanação dos aspectos teóricos do portfólio, do uso e dos objetivos da ferramenta, como ela será trabalhada ao longo do semestre. A professora, ao explicitar as intenções que possui com a avaliação, abre espaço para o aluno explicitar as intenções dele também, assim como as expectativas e receios sobre a construção do portfólio.

Dessa maneira, preconiza-se que, ao início e ao final do portfólio, sejam apresentados textos de autoria do aluno. O texto inicial consiste numa biografia resumida do discente, um texto memorial, no qual o aluno descreva algumas de suas características básicas, interesses pessoais e expectativas quanto ao curso e à disciplina. A conclusão do trabalho deverá fazer uma síntese crítica dos temas abordados ao longo do semestre, bem como avaliar se a disciplina correspondeu às expectativas iniciais apresentadas.

Para compor o corpo do portfólio, as visitas técnicas, os seminários e os assuntos trabalhados em sala de aula devem ser registrados. A cada registro, é atribuída uma pontuação diferenciada, de acordo com a natureza da atividade, conforme mostra o Quadro 2.

Quadro 2 - Distribuição de pontos da disciplina Alimentação e Cultura, do curso de Nutrição da UFMG, 2006 a atual

\begin{tabular}{lc}
\hline \multicolumn{1}{c}{ Atividade } & Pontuação \\
\hline Seminários & 60 pontos \\
Relatório de visitas & 10 pontos \\
Resenhas de filmes e contribuições diversas & 30 pontos \\
\hline
\end{tabular}

Fonte: elaborado pelas autoras, 2016.

A pontuação maior dada aos seminários justifica-se por eles agruparem duas atividades distintas: uma relativa à participação durante a aula e outra relacionada aos registros em portfólio, que deverá conter não só a parte que o aluno apresentou em sala de aula, mas também as reflexões dele sobre o tema geral. A intenção não é que os alunos resumam os assuntos estudados, mas que eles possam resgatar a ideia central dos conteúdos, articulandoos com outras informações que forem buscadas dentro e fora do ambiente acadêmico. Essas informações externas ao contexto de sala de aula podem incluir reportagens de jornal, revistas ou outros textos de interesse. Em adição, essa disciplina permite ao discente ir muito além dos 
textos, encorajando, dessa maneira, que experiências diversas sejam trabalhadas no portfólio, como, por exemplo, as visitas a restaurantes, feiras gastronômicas ou jantares entre amigos e familiares. Outros tipos de construções são igualmente valorizadas, como os registros fotográficos e o uso de elementos literários e culturais, como trechos de músicas e poesias, desde que relacionados às temáticas propostas e que estejam articuladas de forma criteriosa. Com isso, espera-se que os discentes desenvolvam um olhar crítico e reflexivo sobre os temas estudados, possibilitando a integração com a realidade vivida.

Com a adoção do portfólio como ferramenta avaliativa há quase dez anos, alguns ajustes foram necessários, de maneira a melhorar o relacionamento dos discentes com esse instrumento. Além disso, essas modificações foram trabalhadas visando-se atingir o maior envolvimento dos acadêmicos com a atividade. Essas alterações foram feitas na forma de apresentação do portfólio e quanto ao processo avaliativo.

Portanto, inicialmente, a avaliação era feita pela conferência dos seguintes itens:

1. apresentação de referência às várias atividades desenvolvidas;

2. aprofundamento e uso de referências extraclasse;

3. normatização do trabalho;

4. desenvolvimento de texto introdutório e conclusivo.

Dessa forma, a avaliação era realizada em dois níveis: primeiramente, por meio de um olhar mais minucioso, com a verificação da apresentação dos tópicos que foram trabalhados durante a disciplina por meio de um checklist; em segundo lugar, mediante uma avaliação global do trabalho, pensando no portfólio como um todo.

Quanto à alteração na forma de apresentação, em alguns semestres de 2012 e 2013, realizouse a experiência do portfólio online por meio da plataforma Moodle do minhaUFMG, de forma optativa. Entretanto, essa alternativa não se apresentou viável no período, pois, em alguns casos, as postagens eram diárias, demandando muito tempo para o acompanhamento. Ademais, com esse formato, o processo avaliativo ficava centrado nos temas abordados, perdendo-se a referência do aluno como produtor daquele conhecimento.

Com o fim do portfólio virtual, também em 2014, tentou-se uma nova modificação no processo avaliativo, com a inserção da avaliação parcial do material produzido, de forma a 
ser mais coerente com a concepção formativa do portfólio. Assim, foi criado um momento em sala de aula, localizado no meio do semestre letivo, de forma que os alunos pudessem discutir e avaliar o andamento da construção dos portfólios que estavam fazendo. No entanto, foi detectado que muitos não conseguiam fazer uma avaliação real das próprias produções, diante da falta de prática em se autoavaliar e do receio de receber notas baixas.

Ainda no intuito de melhorar a reflexão do aluno sobre o tema da alimentação, no mesmo ano de 2014, foram incluídas as fotografias dos lugares onde se guardam os gêneros alimentícios nas residências dos discentes, e, embora as fotos de geladeiras tenham sido as mais frequentes, também apareceram fotos de armários e fruteiras. Nesse momento, a crítica ao mundo dos fast-foods desloca-se do nível macro, como o que é exposto constantemente na mídia, para o nível micro, representado pela realidade do aluno, e, ao se aproximar do mundo deles, provoca-se uma maior reflexão sobre o tema.

A mais recente modificação, também em 2014, foi a introdução do seminário final da disciplina, no qual o aluno, ao trabalhar com o tema dos vícios alimentares, precisa trazer para o dia do seminário e para o portfólio os conteúdos das demais matérias do primeiro período que contribuíram para a compreensão do assunto escolhido. Essa inclusão formaliza um momento em que a contribuição das outras disciplinas deve aparecer, visto que alguns alunos, ao entenderem o papel do portfólio na aprendizagem, começaram a trazer espontaneamente esse tipo de contribuição para as próprias produções. Ao se estipular essa condição para o desenvolvimento do seminário, força-se uma integração, que felizmente vem obtendo êxito.

Visando, ainda, melhorar a compreensão dos alunos com relação ao processo de autoavaliação, foi implantado, no primeiro semestre de 2015, um checklist (QUADRO 3) a ser utilizado pelos próprios discentes durante a avaliação parcial e final dos portfólios que construíram. 
Quadro 3 - Checklist para autoavaliação do portfólio da disciplina Alimentação e Cultura, do curso de Nutrição da UFMG, 2015 a atual

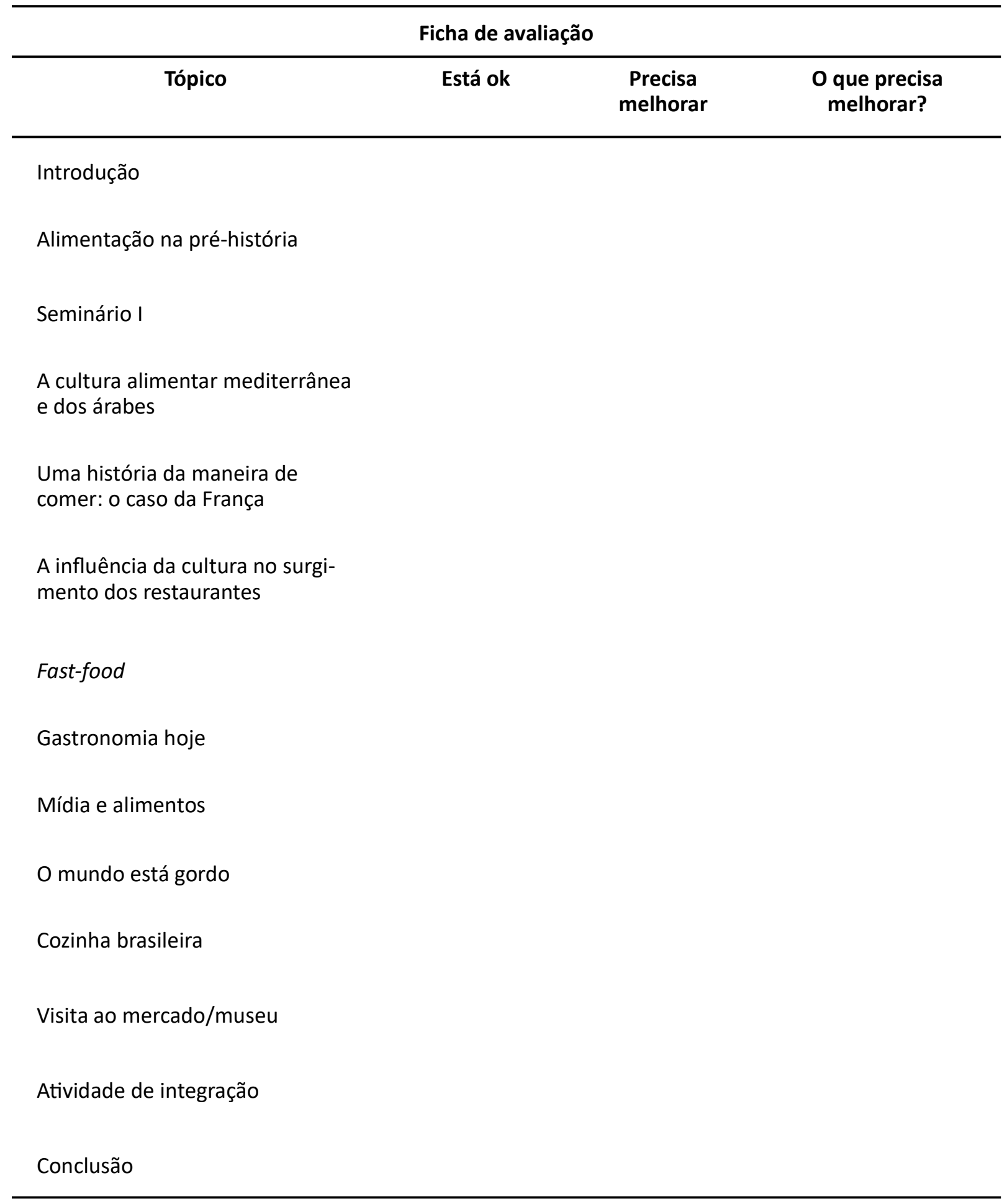

Fonte: elaborado pelas autoras, 2015. 
A intenção com a adoção do checklist foi de convidar os alunos a refletirem sobre a construção e a qualidade das produções que realizaram e a desenvolverem um olhar crítico sobre o próprio processo de aprendizagem por meio do reconhecimento das limitações e potencialidades do trabalho construído. Desse modo, eles deveriam pensar sobre cada item que compõe o trabalho final, de forma a identificar onde era necessário melhorar e como executar esse aprimoramento.

Portanto, com as alterações feitas no processo, foi possível identificar maior estabilidade nas produções. Anteriormente, os trabalhos dos alunos apresentavam níveis bem discrepantes quanto à qualidade, variando de trabalhos excepcionais a portfólios com apresentações inferiores. Desse modo, o número de trabalhos com baixa qualidade foi reduzido.

O uso do portfólio é trabalhado como um instrumento de avaliação contínua e evolutiva do progresso dos alunos. É esperado que os discentes incluam, na composição desse documento, reflexões e críticas sobre os temas tratados ao longo das disciplinas, feitas por meio de materiais diversos. Além disso, é desejável que os discentes sejam capazes de pensar no portfólio como reunião das melhores produções que fizeram, abordando não somente questões acadêmicas, mas elementos das vivências pessoais, conferindo um caráter de identidade ao trabalho. Adicionalmente, pensando sobre o elemento cognitivo da reflexão, relacionado à capacidade de síntese, reafirma-se a importância de se estimular os alunos a entenderem a construção dos portfólios como um processo contínuo de aprendizagem.

\section{DIFICULDADES NA ADOÇÃO DO PORTFÓLIO}

Historicamente, mesmo com todo o debate sobre novas formas de se conduzir o processo de ensino-aprendizagem, os critérios avaliativos que valorizam a classificação dos alunos e a memorização de conteúdos ainda são priorizados no meio acadêmico (NEVES; VALENTINI, 2011). Assim, desde o ingresso no meio escolar, os alunos se familiarizam com esses critérios e os tomam como sendo a única forma realmente válida de provar o aprendizado (MORAES, 2011). Destarte, quando novas ferramentas avaliativas são introduzidas no contexto pedagógico, é de se esperar que haja certa resistência ou dificuldade na assimilação dos princípios apresentados por elas.

Uma atitude de estranhamento semelhante foi observada no trabalho de Rangel (2003), desenvolvido com seis turmas do primeiro período do curso de Odontologia da Universidade 
Estácio de Sá, no Rio de Janeiro. Portanto, pode-se inferir que fazer com que os discentes incorporem novas formas de trabalhar e aprender pode-se mostrar desafiador. Esse fato tem ligação com a interpretação equivocada dos acadêmicos frente à figura do professor, especialmente quando são convidados a dividir a responsabilidade pelo próprio processo de aprendizagem com o docente (ESTEBAN, 1999).

A principal dificuldade encontrada na adoção do portfólio como instrumento avaliativo na disciplina Alimentação e Cultura foi primariamente observada na qualidade das produções dos alunos. De acordo com uma avaliação qualitativa feita com os portfólios entregues no segundo semestre de 2014 e no primeiro semestre de 2015, alguns trabalhos eram constituídos por informações fragmentadas dos conteúdos das disciplinas, sem a devida elaboração e sem crítica ao que era apresentado. Faltavam, em muitos portfólios, itens básicos, como introdução e conclusão do documento. Adicionalmente, diversos textos produzidos pelos alunos caracterizavam-se por reproduções das falas da docente da disciplina, sem desenvolvimento e conclusão adequados.

Mesmo com a melhora dos resultados, obtida por meio das modificações feitas na disciplina Alimentação e Cultura, com a inserção da avaliação parcial do portfólio e o uso da ficha de autoavaliação, ainda que de forma amenizada, observou-se a persistência desse problema. Portanto, é evidente que ainda falta envolvimento e amadurecimento por parte dos acadêmicos com o processo de aprendizagem. Corroborando com a ideia anterior, Silva e Souza (2007) apontaram que 30\% ( $n=6$ indicações) dos materiais publicados no Google Acadêmico, no período de 1996 a 2006, trouxeram a questão do envolvimento e do comprometimento do aluno como um dos principais obstáculos oferecidos ao uso do portfólio.

Outra dificuldade a ser mencionada é que, diante do elevado número de alunos nas disciplinas do curso de Nutrição da UFMG, consistindo em turmas com mais de 35 alunos, torna-se complicado o processo de orientação por parte do docente sobre o uso do portfólio. Diante da característica fundamental do portfólio, de ser construído dentro de um processo reflexivo, com vistas ao crescimento do aluno, o acompanhamento mais próximo dos acadêmicos pelo docente se faria necessário. Assim, esse olhar mais aprofundado sobre o aluno propiciaria melhor aproveitamento da atividade por eles. Contudo, a sobrecarga dos professores universitários é uma realidade que limita o trabalho docente (BORSOI, 2012). A opção por essa ferramenta exige maior disponibilidade, aprofundamento científico e constante estudo 
do docente. Ou seja, o portfólio é uma excelente ferramenta de avaliação formativa, com poder de feedback caracterizado por:

[...] ser regular, bidirecional, enfatizar pontos positivos e negativos, despertar autorreflexão, auxiliar a melhorar o desempenho, promover motivação para aprender, fazer conexão entre o aprendizado e a realidade, aperfeiçoar as habilidades de ensinar e aprender, focar no comportamento observado, observar e fazer comentários específicos (BORGES et al., 2014, p. 326).

\section{CONSIDERAÇÕES FINAIS}

A partir do momento em que a avaliação é entendida não como o fim da educação, mas como um elemento a serviço da aprendizagem, novas formas de se pensar o processo educativo se delineiam. Assim, os métodos e ferramentas avaliativas devem possibilitar ao aluno condições de progredir e de ser agente do próprio percurso cognitivo, e não devem consistir na reprodução de mecanismos de repressão, classificação e exclusão presentes na sociedade (RANGEL, 2003).

Portanto, o portfólio deve refletir não só o desenvolvimento acadêmico e cognitivo do discente em sentido estrito, mas deve considerar igualmente os aspectos afetivos que perpassam a produção do material. O que fica evidente é que a implementação dessa ferramenta é uma ruptura com o modelo quantitativo de avaliação, passando para um processo multidimensional, bidirecional, solidário e coletivo de ensino-aprendizagem, respeitando as diferentes formas pelas quais indivíduos diferentes aprendem e significam o mundo (RANGEL, 2003; REZENDE, 2010). Adicionalmente, o uso desse instrumento aponta para as práticas reflexivas produtoras de indivíduos indagadores (SCHÖN, 2000).

Mesmo em face do reconhecimento das potencialidades da ferramenta dentro dos processos de ensino-aprendizagem, o uso do portfólio é pouco adotado no ensino superior, diante da dificuldade em se definir o protagonismo do estudante (REZENDE, 2010). Além disso, existe uma cultura de valorização das avaliações somativas como procedimentos associados ao rigor técnico e a possibilidade de classificação.

Outro aspecto relevante da adoção do portfólio está no crescimento do próprio professor. O portfólio, sendo individual e prenhe de possibilidades para o aluno expor o próprio 
percurso, torna-se um instrumento avaliativo que leva diversas contribuições, também ao docente, durante o processo de avaliação. Ao contrário das provas de conteúdo específico, o portfólio aceita bem o inusitado, o diferente e consequentemente traz algo de novo para o conhecimento do professor. É comum tomar conhecimento de temas desconhecidos ou sobre os quais o professor tinha conhecimento apenas superficial, a partir da leitura do portfólio do discente. $\mathrm{O}$ docente deixa de ser o único detentor do conhecimento a ser avaliado e passa a ser um receptor de novos conhecimentos vindos do aluno. Sem a dependência do professor, o aluno pode desenvolver o tão sonhado "aprender a aprender" que só tem a beneficiá-lo na formação como profissional autônomo, e o próprio professor, caracterizado como o único transmissor do conhecimento, passa a aprender por meio do discente.

Assim, mesmo com as dificuldades vivenciadas na adoção desse instrumento de avaliação, por vezes marcada pelo pouco envolvimento do acadêmico e pela falta de disponibilidade docente para um acompanhamento mais próximo, a opção por essa ferramenta é positiva. A experiência mostra que mesmo aqueles alunos que não se envolvem com o processo adequadamente ainda são capazes de apreender algo com a construção do portfólio e de produzir um conhecimento mais duradouro, mais que simplesmente reproduzir um conteúdo. O professor leitor, observador, avaliador e aprendiz, a cada ano, incorpora novos conceitos e leituras, aprimora a crítica e a reflexão sobre o fazer como professor, e essa autorreflexão o encoraja a adotar novas abordagens e aperfeiçoar a forma de avaliar. Quanto mais o professor conseguir aproximar a avaliação da realidade dos alunos, melhor resposta conseguirá nas avaliações.

O uso do portfólio, por todos esses motivos, continua sendo o principal instrumento de uma disciplina que trata de cultura e alimentação no primeiro período. O primeiro período é o início da relação acadêmica do aluno com a nutrição, mas não é o primeiro contato dele com o tema da cultura nem com o da alimentação. Sobre essas duas temáticas, o aluno chega com bagagem que deve ser explorada e exposta a novos conhecimentos, para fundamentar a crítica e a reflexão. Com o portfólio, o discente conhece uma possibilidade real de construir um conhecimento e, mais que isso, aprende outro modo de lidar com o conhecimento, que vai além da reprodução de conteúdo, e isso é fundamental para prepará-lo para a vida profissional. Ao buscar conteúdos novos, refletir e criticar, o aluno vai ganhando segurança para expressar os conhecimentos adquiridos, o que é desejável pelo currículo do curso. 


\section{REFERÊNCIAS}

BITTENCOURT, E.; BELLI, J. I. R. Portfólios: instrumento de ensino. In: CONGRESSO BRASILEIRO DE ENSINO EM ENGENHARIA, 34, 2006, Passo Fundo, Anais... Passo Fundo: ABENGE, 2006. Disponível em: <http://www.abenge.org.br/CobengeAnteriores/2006/ artigos/1_273_472.pdf>. Acesso em: 2 maio 2016.

BORGES, M. C. et al. Avaliação formativa e feedback como ferramenta de aprendizado na formação dos profissionais da saúde. Medicina, Ribeirão Preto, v. 47, n. 3, p. 324-331, jul./set., 2014. Disponível em: <http://revista.fmrp.usp.br/2014/vol47n3/11_Avaliacaoformativa-e-feedback-como-ferramenta-de-aprendizado-na-formacao-de-profissionaisda-saude.pdf>. Acesso em: 9 maio 2016.

BORSOI, I. C. F. Trabalho e produtivismo: saúde e modo de vida de docentes de instituições públicas de ensino superior. Cadernos de Psicologia Social do Trabalho, São Paulo, v. 15, n. 1, p. 81-100, jul. 2012. Disponível em: <http://dx.doi.org/10.11606/issn.1981-0490. v15i1p81-100>. Acesso em: 3 maio 2016.

BRUZZI, R. C. V. et al. Auto-avaliação no ensino superior: um espelho chamado portfólio. Linhas Críticas, Brasília, v. 7, n. 13, p. 289-303, jul./dez., 2001. Disponível em: <http:// periodicos.unb.br/index.php/linhascriticas/article/view/6543/5273>. Acesso em: 2 maio 2016.

ESTEBAN, M. T. A avaliação no cotidiano escolar. In: ESTEBAN, M. T. (org.). Avaliação: uma prática em busca de novos sentidos. Rio de Janeiro: DP\&A, 1999, p. 7-28.

HYPOLLITO, D. O uso do portfólio, a reflexão e a avaliação. Integração, São Paulo, ano v, n. 19, p. 291-292, nov. 1999. Disponível em: <http://www.usjt.br/proex/arquivos/ produtos_academicos/291_19.pdf>. Acesso em: 3 maio 2016.

MIRANDA, J. R. A avaliação das aprendizagens na educação de jovens e adultos por meio do portfólio. 2011. 251 f. Tese (Doutorado em Educação) - Faculdade de Educação, Universidade de Brasília, Brasília, 2011. Disponível em: <http://repositorio.unb.br/ bitstream/10482/9697/1/2011_JosevalReisMiranda.pdf>. Acesso em: 3 maio 2016.

MORAES, D. A. F. Prova: instrumento avaliativo a serviço da regulação do ensino e da aprendizagem. Estudos em Avaliação Educacional, São Paulo, v. 22, n. 49, p. 233-258, maio/ago. 2011. Disponível em: <http://www.fcc.org.br/pesquisa/publicacoes/eae/ arquivos/1636/1636.pdf>. Acesso em: 2 maio 2016.

NEVES, I. C.; VALLENTINI, M. T. P. Avaliação da aprendizagem nos cursos de licenciatura: uma discussão em aberto. Revista Voos, Guarapuava, v. 4, n. 1, p. 47-53, mar. 2008. 
Disponível em: <http://www.revistavoos.com.br/seer/index.php/voos/article/ view/197/05_NESC01_2008>. Acesso em: 4 maio 2016.

OLIVEIRA, E. S. G. et al. Uma experiência de avaliação da aprendizagem na educação a distância. O diálogo entre avaliação somativa e formativa. REICE, Madrid, v. 5, n. 2, p. 39-55, 2007. Disponível em: <http://www.rinace.net/arts/vol5num2e/art4.pdf>. Acesso em: 4 maio 2016.

PORTFÓLIO. In: MICHAELIS Dicionário. São Paulo: Melhoramentos, 2009, 992 p.

RANGEL, J. N. M. O portfólio e a avaliação no ensino superior. Estudos em Avaliação Educacional, São Paulo, n. 28, p. 145-160, jul./dez., 2003. Disponível em: <http://www. fcc.org.br/pesquisa/publicacoes/eae/arquivos/1148/1148.pdf $>$. Acesso em: 2 maio 2016.

REZENDE, M. A. R. A relação pedagógica e a avaliação no espelho do portfólio: memórias docentes e discentes. 2010. 279 f. Tese (Doutorado em Educação) - Faculdade de Educação, Universidade Federal de Minas Gerais, Belo Horizonte, 2010. Disponível em: <http://hdl.handle.net/1843/FAEC-87YPQC>. Acesso em: 5 maio 2016.

SCHÖN, D. A. Educando o profissional reflexivo: um novo design para o ensino e a aprendizagem. Tradução de Roberto Cataldo Costa. Porto Alegre: Artmed, 2000.

SCRIVEN, M. The metodology of evaluation. In: TYLER, R.; GAGNÉ, R. M.; SCRIVEN, M. (Ed.). Perspectives of curriculum evaluation. Chicago: Rand Mac Nally, p. 39-83, 1978.

SILVA, M. J. P.; SOUZA, N. A. Portfólio: limites e possibilidades em uma avaliação formativa. In: EDUCERE, 7, 2007, Curitiba, Anais... Curitiba: Champagnat, 2007. Disponível em: $<$ http://www.pucpr.br/eventos/educere/educere2007/anaisEvento/arquivos/Cl-137-05. pdf>. Acesso em: 2 maio 2016.

UNIVERSIDADE FEDERAL DE MINAS GERAIS. Escola de Enfermagem. Projeto de criação do Curso de Graduação em Ciências da Nutrição da Universidade Federal de Minas Gerais. Belo Horizonte, 2003. 88 p.

UNIVERSIDADE FEDERAL DE MINAS GERAIS. Escola de Enfermagem. Programa da Disciplina Alimentação e Cultura. Belo Horizonte, [20-]. 3 p. 


\section{Aline Viveiros}

Mestre em Enfermagem (UFMG), atuando na linha de pesquisa de Educação em Saúde e Enfermagem. Nutricionista. Especialista em Gestão, Qualidade e Segurança em Alimentação para Coletividades (Estácio de Sá).

alinev89@gmail.com

\section{Rita de Cássia Marques}

Doutora em História pela Universidade Federal Fluminense (2003), com mestrado em História pela Universidade Federal de Minas Gerais (1995) e graduada em História pela Universidade Federal de Minas Gerais (1986). Atualmente é professora associada da Escola de Enfermagem da Universidade Federal de Minas Gerais. Tem experiência na área de História, com ênfase nos seguintes temas: Belo Horizonte, história, médicos, doença e ciências.

rcmarques23@gmail.com 